\title{
Термоэлементы из твердых растворов халькогенидов висмута и сурьмы
}

\author{
(С Л.Д. Иванова ${ }^{1}$, И.Ю. Нихезина ${ }^{1}$, Ю.В. Гранаткина ${ }^{1}$, В.А. Дударев ${ }^{1}$, С.А. Кичик ${ }^{2}$, А.А. Мельников ${ }^{2}$ \\ ${ }^{1}$ Институт металлургии и материаловедения им. А.А. Байкова Российской академии наук, \\ 119334 Москва, Россия \\ 2 ООО НПО „Кристалл“, \\ 141060 Королев, Московская обл., Россия \\ E-mail: ivanova@imet.ac.ru
}

(Получена 31 января 2017 г. Принята к печати 15 февраля 2017 г.)

Исследованы термоэлементы для термоэлектрических холодильников из мелкокристаллических материалов на основе твердых растворов халькогенидов сурьмы и висмута $p$ - и $n$-типов проводимости, полученных горячим прессованием и экструзией из порошков, приготовленных спиннингованием расплава. Проведены расчет характеристик модулей в интервале $100-400 \mathrm{~K}$ с учетом температурных зависимостей термоэлектрических параметров материалов его ветвей и оценка согласования ветвей по термоэлектрическим параметрам. Изготовлены модули и проведено сравнение экспериментальных и расчетных характеристик.

DOI: $10.21883 /$ FTP.2017.08.44779.48

\section{1. Введение}

В конце XX-начале XXI веков предложена новая концепция повышения термоэлектрической эффективности материалов $Z\left(Z=\alpha^{2} \sigma / \kappa\right.$, где $\alpha, \sigma, \kappa-$ это коэффициент Зеебека, электропроводность и теплопроводность), основанная на создании наноструктур. Как оказалось, такие структуры можно получить методами порошковой металлургии, используя наноразмерные порошки или частицы и фракции, полученные методами быстрой закалки расплава. При этом важно, чтобы материалы для $p$ - и $n$-ветвей были согласованными по термоэлектрическим параметрам.

В настоящей работе рассмотрены различные сочетания термоэлементов из мелкокристаллических материалов на основе твердых растворов халькогенидов висмута и сурьмы, полученные компактированием порошка, приготовленного спиннингованием расплава.

\section{2. Экспериментальные результаты}

При спиннинговании расплава твердых растворов халькогенидов висмута и сурьмы порошок получается в виде пластинок, состоящих из тонких чешуек, плоская сторона которых перпендикулярна охлаждаемой поверхности диска. При прессовании или экструзии пластинки распадаются на эти чешуйки, и получаются достаточно мелкозернистые образцы. Для таких образцов $p$-типа проводимости $Z_{\max } \sim 3.5 \cdot 10^{-3} \mathrm{~K}^{-1}$ при $300 \mathrm{~K} \quad[1]$. Для образцов $n$-типа проводимости при использовании спиннингованной фракции $Z_{\max } \sim 2.5 \cdot 10^{-3} \mathrm{~K}^{-1}$ при $300 \mathrm{~K}[2]$.

С использованием метода Гаусса для решения систем линейных уравнений было разработано программное обеспечение для расчета добротности $Z_{\text {eff }}$ и максимального перепада температур $\Delta T_{\max }$ термоэлементов с температурой горячего спая $100-400 \mathrm{~K}$. При расчетах использованы формулы, приведенные в работе [3].
В виде таблиц вводятся следующие величины: коэффициент Зеебека $\alpha$, удельная электропроводность $\sigma$ и теплопроводность $\kappa$, полученные по результатам измерений материалов для $p$ - и $n$-ветвей модулей при $100-400$ K. $Z$ модуля рассчитывается по формуле:

$$
Z_{\text {mod }}=\left(\alpha_{p}+\alpha_{n}\right)^{2}\left(\sigma_{p}+\sigma_{n}\right) /\left(\kappa_{p}+\kappa_{n}\right) / 4 .
$$

Для расчетов используются экспериментальные величины $\alpha, \sigma, \kappa$ для $p$ - и $n$-ветвей при пяти температурах. Для определения $\alpha, \sigma, \kappa$ при любой температуре в интервале $100-400 \mathrm{~K}$ по экспериментальным данным строятся интерполирующие полиномы. Коэффициенты этих полиномов находят путем решения системы линейных уравнений метода наименьших квадратов с использованием алгоритма Гаусса. Полученные значения $\alpha$, $\sigma, \kappa$ подставляют в формулу (1) и определяют добротность модуля $Z_{\bmod }$ при заданных температурах. Так как найти $Z_{\text {eff }}$ и $\Delta T_{\max }$ путем аналитического решения уравнений нельзя, то применяли численное решение методом итераций.

Для каждой искомой температуры $T_{\Gamma}$ итеративно рассчитывают значения $Z_{\mathrm{eff}}$ и $\Delta T_{\max }$

1) $\Delta T_{\max }=\left(\sqrt{1+2 Z_{\text {eff }} t T_{\Gamma}}-1\right) / 2 Z_{\text {eff }}(t)$ (перепад температур, зависящий от $Z_{\mathrm{eff}}(t)$ и температуры горячего слоя $T_{\Gamma}$, при расчетах принимают $Z_{\mathrm{eff}}=Z_{\bmod }$ при текущей температуре $t=T_{\Gamma}$ на первом шаге);

2) $T_{x}=T_{\Gamma}-\Delta T_{\max }$ (температура холодного слоя);

3) $t=T_{x}+\Delta T_{\max } / 2$ (температура для следующей итерации расчета).

4) Переход к п. 1: снова рассчитывается $\Delta T_{\max }$ по формуле из п. 1 , считая $Z_{\mathrm{eff}}(t)=Z_{\bmod }(t)$ при температуре $t$, полученной в п. 3 , и сравнивают его с предыдущим значением $\Delta T_{\max }$. Если разница больше требуемой погрешности расчетов, еще раз повторяют последовательность шагов (в данном случае была принята погрешность $0.1 \mathrm{~K}$ ). Если погрешность меньше принятой, то полученные на последнем шаге значения 
Характеристики модулей $\left(Z_{\mathrm{eff}}, T_{\max }\right)$ и соотношение сечений ветвей $\left(S_{p} / S_{n}\right)$ при комнатной температуре (№№ ветвей см. рис. 1 и 2$)$

\begin{tabular}{c|c|c|c|c|c|c|c}
\hline \multirow{2}{*}{ Модуль } & $\begin{array}{c}\text { № } \\
\text { р-ветви }\end{array}$ & $\begin{array}{c}\text { № } \\
n \text {-ветви }\end{array}$ & $\begin{array}{c}\alpha_{p}, \\
\text { мкB/K }\end{array}$ & $\begin{array}{c}\alpha_{n}, \\
\text { мкB/K }\end{array}$ & $S_{p} / S_{n}$ & $\begin{array}{c}Z_{\text {eff }} \cdot 10^{3}, \\
\mathrm{~K}^{-1}\end{array}$ & $\begin{array}{c}\Delta T_{\max }, \\
\mathrm{K}\end{array}$ \\
\hline M1 & 1 & 4 & 226 & -204 & 1.4 & 2.6 & 68.2 \\
M2 & 1 & 5 & 226 & -198 & 1.2 & 2.7 & 69.9 \\
M3 & 2 & 4 & 224 & -204 & 0.9 & 2.5 & 65.3 \\
M4 & 2 & 5 & 224 & -198 & 0.8 & 2.5 & 67.8 \\
M5 & 3 & 4 & 208 & -204 & 1.15 & 2.47 & 66.6 \\
М6 & 3 & 5 & 208 & -198 & 0.99 & 2.6 & 68.3
\end{tabular}
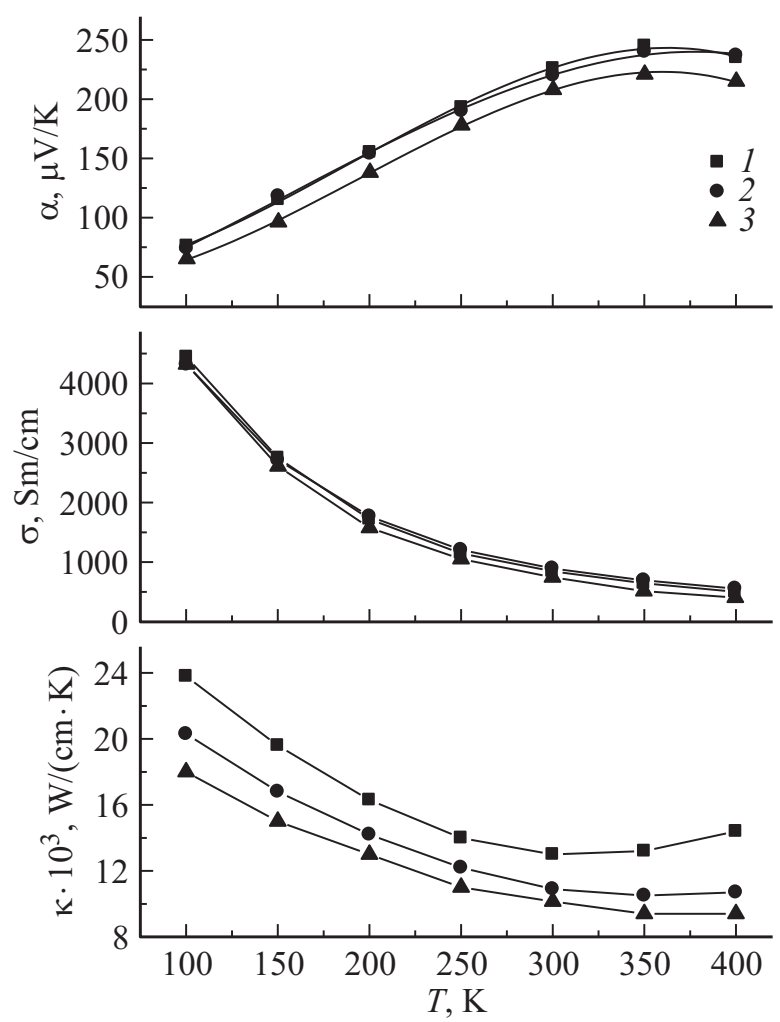

Рис. 1. Температурные зависимости коэффициента Зеебека, электропроводности и теплопроводности образцов $p$-типа проводимости.

для $Z_{\text {eff }}$ и $\Delta T_{\max }$ считают конечными. Результаты расчетов представляются в программе в виде таблиц и графиков зависимостей $\Delta T_{\max }$ и $Z_{\mathrm{eff}}$ от $T_{\Gamma}$ модулей в интервале $100-400 \mathrm{~K}$.

На рис. 1 и 2 приведены зависимости $\alpha(T), \sigma(T)$ и $\kappa(T)$ в интервале $100-400 \mathrm{~K}$ материалов, для которых был проведен расчет характеристик термоэлементов. Материалы для $p$-ветвей на основе твердого раствора $\mathrm{Bi}_{0.5} \mathrm{Sb}_{1.5} \mathrm{Te}_{3}$ получали экструзией (№ 1) и горячим прессованием порошка, полученного спиннингованием расплава (№№ 2,3). Материалы для $n$-ветвей получали горячим прессованием порошка, приготовленного спиннингованием расплава твердого раствора $\mathrm{Bi}_{2} \mathrm{Te}_{2.7} \mathrm{Se}_{0.3}$, легированного $\mathrm{CdCl}_{2}$ (№№ 4,5). Рассмотрены модули с разными сочетаниями ветвей из этих материалов.
В таблице приведены расчетные значения $\Delta T_{\max }$ и $Z_{\text {eff }}$ модулей при комнатной температуре.

Результаты расчетов температурных зависимостей $\Delta T_{\max }$ и $Z_{\text {eff }}$ модулей в интервале $100-400 \mathrm{~K}$ приведены на рис. 3.

При одинаковой длине ветвей оптимальное соотношение их сечений зависит от электропроводности и теплопроводности материалов ветвей: $S_{p} / S_{n}=$ $=\sqrt{\kappa_{p} \sigma_{p} / \kappa_{n} \sigma_{n}}$ [3]. Эти величины также приведены в таблице и на рис. 3 .


Рис. 2. Температурные зависимости коэффициента Зеебека, электропроводности, и теплопроводности образцов $n$-типа проводимости. 

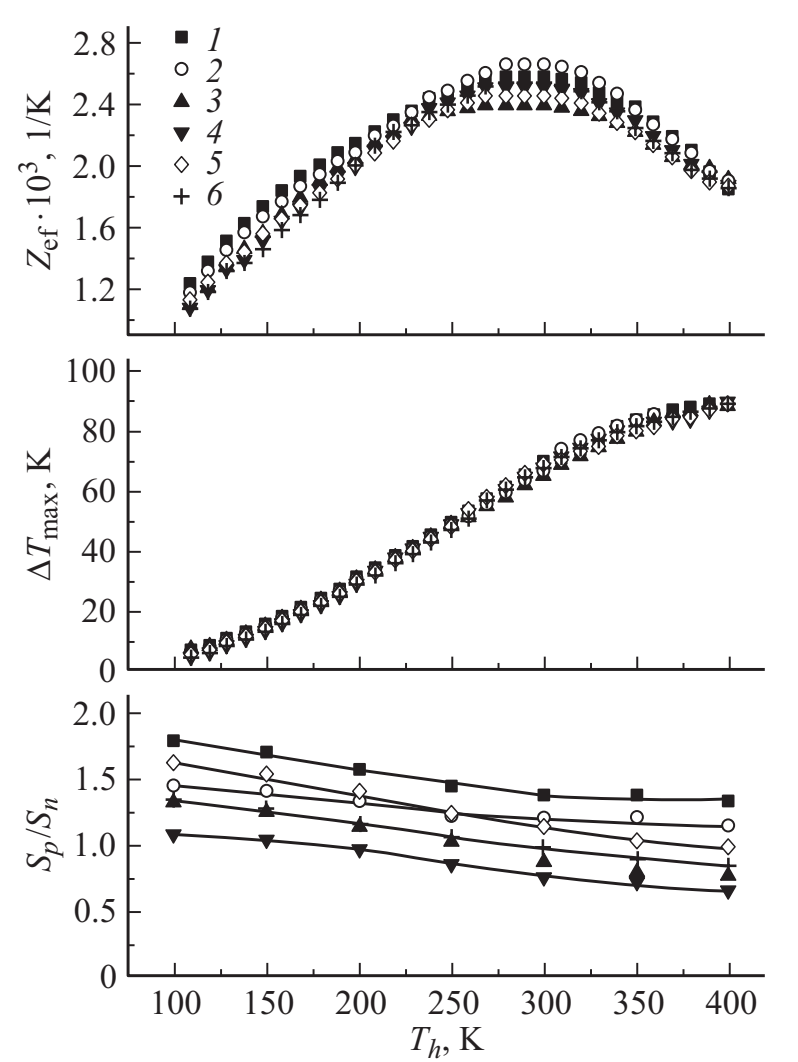

Рис. 3. Температурные зависимости эффективной термоэлектрической добротности, максимального перепада температур и оптимальных соотношений сечений ветвей для модулей M1-M6 (1-6 соответственно) (см. таблицу).

Рассчитанные максимальные значения $Z_{\mathrm{eff}}$ всех исследованных модулей с $n$-ветвями из горячепрессованных материалов, и $p$-ветвями, полученными горячим прессованием и экструзией порошков, полученных спиннингованием расплава, составили величину $Z_{\text {eff }}=(2.55 \pm 0.2) \cdot 10^{-3} \mathrm{~K}^{-1}$ в интервале температур от 320 до $250 \mathrm{~K}$. Ветви модулей М2-M6 хорошо согласованы по параметрам, и оптимальное соотношение ветвей в этой области температур составило $S_{p} / S_{n} \sim 1.0$.

Для проверки расчетов были изготовлены модули из материалов, свойства которых приведены на рис. 1 (№ 1,3, p-ветвь и 2 (№ 4, 5, n-ветвь), М1, М2, М5, М6 (см. таблицу). Каждый модуль состоял из 6 пар (12 ветвей). Все ветви были одного размера $1.4 \times 1.4 \times 1.6 \mathrm{мм}$. Методом Хармана измерен $Z$ модулей в интервале $300-400 \mathrm{~K}$ и электропроводность модулей. Измерения проводили в вакууме с учетом потерь по проводам и контактных сопротивлений.

Максимальные значения ZT хорошо согласуются с расчетными для модулей М5 и М6 и составляют величины 0.85 и 0.86 (по расчетным данным) и 0.79 , и 0.8 (по результатам эксперимента) соответственно, т. к. оптимальные соотношения сечений $p$ - и $n$-ветвей этих модулей близки к 1. Для модулей M1 и M2 расчетные и экспериментальные величины $\left(Z T_{\max }\right)$ заметно отличаются: расчетные 0.90 и 0.91, а экспериментальные -
0.69 и 0.78 соответственно, что связано с несогласованностью сечений $p$ - и $n$-ветвей $\left(S_{p} / S_{n}=1.4\right.$ и 1.2$)$. Электропроводность измеренных модулей в интервале $300-400 \mathrm{~K}$ изменялась от $\sim 700$ до $\sim 500 \mathrm{CM} / \mathrm{cm}$.

\section{3. Заключение}

Получение порошков с помощью спиннингования расплава и последующее их компактирование горячим прессованием или экструзией позволяет изготовить материалы на основе твердых растворов халькогенидов висмута и сурьмы для $p$ - и $n$-ветвей термоэлектрических устройств с согласованными характеристиками, не уступающими параметрам лучших материалов, полученных методами направленной кристаллизации.

Использование программы расчета добротности и максимального перепада температур на термоэлементах, учитывающей температурные зависимости термоэлектрических параметров материалов ветвей, позволяет оценить наиболее выгодные сочетания этих материалов.

Работа выполнена при финансовой поддержке РФФИ, проект № 13-08-00041a.

\section{Список литературы}

[1] Л.Д. Иванова, Л.И. Петрова, Ю.В. Гранаткина, В.Г. Леонтьев, А.С. Иванов, С.А. Варламов, Ю.П. Прилепо, А.М. Сычев, А.Г. Чуйко, И.В. Башков. Неорг. матер., 49 (2), 110 (2013).

[2] Л.Д. Иванова, Л.И. Петрова, Ю.В. Гранаткина, С.А. Кичик, И.С. Маракушев, А.А. Мельников. Неорг. матер., 51 (7), 808 (2015).

[3] Л.И. Анатычук, В.А. Семенюк. Оптимальное управление свойствами термоэлектрических материалов и приборов (Черновцы „ПРУТ“, 1992) 263 с.

Редактор Г.А. Оганесян

\section{Thermoelements from antimony and bismuth chalcogenide solid solutions}

\author{
L.D. Ivanova' ${ }^{1}$, I.Yu. Nikhezina' ${ }^{1}$, Yu.V. Granatkina', \\ V.A. Dudarev', S.A. Kichik², A.A. Mel'nikov' \\ ${ }^{1}$ Russian Academy of Sciences Baikov Institute \\ of Metallurgy and Materials Science, \\ 119334 Moscow, Russia \\ ${ }^{2}$ Crystal Ltd., \\ 141060 Korolev, Moscow region, Russia
}

\begin{abstract}
Thermoelements for thermoelectric coolers from finecrystalline materials based on antimony and bismuth chalcogenide solid solutions of $p$ - and $n$-type conductivities, obtained by hot pressing and extrusion fromp powders, made by melt spinning, were studied. Calculations of modules' properties were performed in the range of $100-400 \mathrm{~K}$, taking into account temperature dependencies of thermoelectric parameters of legs, and the parameters of thermoelectric legs' matching are estimated. The modules are produced and the experimental and calculated properties comparison is conducted.
\end{abstract}

